\title{
Susceptibilidad de los búfalos de agua frente a diferentes enfermedades infecciosas
}

\author{
Grazziotto, N.M.'; Maidana, S.S. ${ }^{1,2}$; Romera, S.A. ${ }^{1,2,3}$ \\ ${ }^{1}$ Instit.Virología INTA-CONICET, Hurlingham (Bs.As. Argentina). \\ ${ }^{2}$ Fac.Cs.Exactas, Quím.\& Nat, Univ.Morón. ${ }^{3}$ Fac.Vet.Univ.Salvador. \\ E-mail: grazziotto.noelia@inta.gob.ar
}

\begin{abstract}
Resumen
Grazziotto, N.M.; Maidana, S.S.; Romera, S.A. Susceptibilidad de los búfalos de agua frente a diferentes enfermedades infecciosas. Rev. Vet. 31: 2, 215-223, 2020. En Argentina, los búfalos de agua representan una alternativa económica importante en la cría de ganado. Tales animales se emplean mayormente en la producción de carne y leche. La especie se encuentra estrechamente relacionada al ganado bovino, existiendo en la actualidad una amplia cantidad de campos de producción mixta búfalo-bovino en nuestro país. Se ha demostrado que el ganado bubalino, a pesar de su resistencia a las enfermedades, es susceptible a gran parte de los virus que afectan al rodeo bovino. El objetivo de esta revisión es relevar la importancia del rol del búfalo en el mundo en general y en Argentina en particular, así como destacar la susceptibilidad del ganado bubalino a diferentes enfermedades infecciosas, particularmente virales, enfatizando su rol como reservorio de gérmenes patógenos de otras especies.
\end{abstract}

Palabras clave: búfalos, enfermedades virales, bacterianas y parasitarias, calidad de carne, seguridad humana.

\begin{abstract}
Grazziotto, N.M.; Maidana, S.S.; Romera, S.A. Susceptibility of the water buffalos in front of different infectious illnesses. Rev. Vet. 31: 2, 215-223, 2020. In Argentina, water buffalos represents an important economic alternative in livestock breeding. They are used mostly in the production of meat and milk. This species is closely related to cattle because there is currently a large number of mixed buffalo-bovine production fields in our country. It has been shown that buffaloes, despite their resistance to diseases, are susceptible to a large part of the viruses that affect the bovine herd. The objective of this review is to highlight the importance of the role of the buffalo in the world and in Argentina, the susceptibility of buffalo cattle to different infectious diseases, mainly viral and the role as a reservoir of pathogens of other species.
\end{abstract}

Key words: buffalos, viral, bacterial and parasitic illnesses, meat quality, human security.

\section{Objetivo}

En esta revisión se exponen reportes de diferentes patógenos hallados en búfalos hasta la fecha, mostrando así la susceptibilidad de los mismos y su rol epidemiológico en las enfermedades de interés pecuario. Se destaca además la importancia del control sanitario del ganado bubalino, tanto por su bienestar como por su significación en la actividad ganadera.

\section{Los búfalos en el mundo}

Los "búfalos de agua" (Bubalus bubalis) son de origen asiático, oriundos del continente más extenso de la tierra. Se distribuyen principalmente en las zonas tropical y subtropical del Asia. En la India existen

Recibido: marzo 2020/ Aceptado: junio 2020 hallazgos arqueológicos que demuestran su presencia desde 60.000 a.c. (años antes de Cristo).

Se cree que fueron domesticados hace unos 3.000 a.c. en India, Irak y China. Desde allí habrían sido llevados al África y luego a Europa, Oceanía y -recientemente-al continente americano.

El 97\% de la existencia de B. bubalis aún se encuentra en el continente asiático. Este porcentaje involucra unos 158 millones de cabezas bubalinas. Le siguen Cercano Oriente con 3,9 millones, América del Sur con 1,4 millones, América del Norte-Central con 0,5 millones y Europa con 0,2 millones de cabezas.

\section{Generalidades de los bubalinos}

Según su apariencia, hábitos y usos, estos animales se han clasificado en búfalos de río y de pantano ${ }^{1}$. Las razas existentes en el mundo son 19, incluyendo al bú- 
falo de pantano -también llamado Carabao- el cual es destinado principalmente al trabajo y a la producción de carne. Las 18 razas restantes usualmente se denominan búfalos de río y son utilizadas para producción de carne y leche.

La clasificación zoológica de los búfalos de agua transitó por diferentes categorizaciones a partir de los conceptos de familia, subfamilia, género y especie, en dependencia del desarrollo de la citogenética y más recientemente de la biología molecular.

Los búfalos pertenecen al reino animal, phylum Chordata, subphylum Vertebrata, clase Mammalia, subclase Eutheria, orden Artiodactyla, familia Bovidae, subfamilia Bubalinae, género Bubalus y especies $B u b-$ alis bubalis ("búfalo de río" o "búfalo de agua", con 50 pares de cromosomas) o Bubalis kerebau ("búfalo de pantano" o "carabao", con 48 pares de cromosomas).

La vida útil de los búfalos es de aproximadamente 18 años, con un total de 12 partos durante su etapa productiva. La lactancia perdura unos 240 a 250 días ${ }^{34}$.

B. bubalis es un herbívoro rumiante que se alimenta de forrajes. Al igual que las demás especies bovinas, las gramíneas son la principal fuente de alimentación para su desarrollo, crecimiento y mantenimiento. Es una especie que aprovecha eficientemente el desarrollo de sus pre estómagos, lo cual permite una intensa fermentación microbiana de los alimentos forrajeros.

En estado salvaje los búfalos viven en grupos de hasta 1000 ejemplares, y durante la época de celo los machos forman harenes de hembras. La mitad del tiempo lo pasan sumergidos en el agua o nadando en los pantanos, alimentándose de hierbas ${ }^{9}$.

A diferencia del vacuno, los búfalos admiten mayor presencia de seres humanos. Su docilidad depende del trabajo que realicen sus criadores. La ausencia prolongada de arreos y manejo en los rebaños extensivos, hace que los búfalos se tornen más difíciles de manejar. Son animales fácilmente asustadizos, por lo cual deben ser tratados con orden y tranquilidad.

Se ha reportado que aplicando protocolos con normas de bienestar animal en el manejo del rodeo bubalino, se impacta en mejoras de su productividad. Desde 2007 las búfalas lecheras están incluidas en la lista del "welfare quality" (protocolo del sistema de bienestar animal). En 2009 se demostró que la provisión de una piscina y un amplio lote al aire libre, pueden tener efectos beneficiosos sobre el comportamiento, el bienestary la producción de leche de las búfalas, recomendándose su inclusión en las granjas ubicadas en áreas cálidas ${ }^{13}$.

Existen varios protocolos para apreciar el grado de estrés/bienestar de los rodeos bubalinos. Su evaluación consiste en principios y criterios relacionados con el ambiente y los recursos disponibles para el animal (espacio, instalaciones, tipo de suelo y condiciones climáticas). Otros se basan en el manejo (estrategias de rutina de ordeño y manejo de la salud).

Más recientemente se han incluido indicadores basados en la conducta (comportamiento agonístico, limpieza individual y presencia de miedo), la salud (condición corporal, lesiones, integridad de la ubre) y sobre aspectos fisiológicos (frecuencias cardiaca y respiratoria) ${ }^{13}$.

Los animales criados para la producción de carne están sujetos inevitablemente a ciertos eventos y procedimientos dolorosos y estresantes durante su vida. En el caso de los búfalos de agua, el riesgo de deterioro del bienestar puede ser mayor que en otras especies debido a diversos factores. Sin embargo, es importante tener en cuenta que ha habido poca investigación sobre los efectos de los procedimientos de manejo ante mortem, el aturdimiento y los métodos de sacrificio en esta especie.

La legislación específica y los programas de capacitación de manejadores en países desarrollados y en desarrollo, deben implementarse para tratar de reducir los riesgos del bienestar bubalino durante todas las etapas ante mortem, incluidos el manejo, la carga, la descarga, el transporte, el comercio en el mercado de ganado y el sacrificio.

Muchos de esos puntos se relacionan con el perfeccionamiento de la educación y la comunicación con los ganaderos, peones, faenadores y personal ad hoc, para resaltar la importancia de mejorar el bienestar no solo por el bien de los animales, sino también para aumentar la productividad de la carne y mejorar la seguridad humana ${ }^{12}$.

Los búfalos necesitan agua potable para beber, además de sombra. Poseen poca protección solar debido a que ellos no irradian con facilidad el calor que reciben y generan, además de tener escasa capacidad de transpirar porque poseen una décima parte de glándulas sudoríparas en comparación con el vacuno. Además, su pelaje negro absorbe mayor radiación solar que los animales que poseen capas más claras.

Su carácter semiacuático se evidencia en la habilidad de pastorear forrajes sumergidos. Prefieren revolcaderos, que muchas veces preparan ellos mismos. Además, instintivamente seleccionan zonas de agua limpia para beber, otras zonas para revolcarse y otras para defecar, para ello utilizan ríos, arroyos, lagos y charcos. Cabe destacar que los revolcaderos que crean, ayudan a eliminar los ectoparásitos.

El búfalo es una especie rústica y adaptable a diferentes ecosistemas. Tiene buena capacidad para aprovechar diversas fuentes de pastos y forrajes, especialmente los de baja calidad. Realiza una mejor utilización de estos alimentos que el ganado vacuno. "Ramonea" más que el vacuno y en ocasiones, se sumerge hasta 2 metros de profundidad para alimentarse de plantas que crecen en el fondo de ríos y lagunas ${ }^{10,11}$.

\section{Los búfalos en América}

Se estima que en el continente americano existen más de 4.200 .000 búfalos. Los países americanos con mayor población bubalina son Brasil con 3.500 .000 cabezas, Venezuela con 350.000 , Argentina con 132.000 y Colombia con $170.000{ }^{37}$. Los rebaños bubalinos de 
diferentes países sudamericanos tuvieron su origen por importaciones realizadas desde Australia, Bulgaria, Egipto, India, Italia, Rumania y sudoeste asiático.

Los búfalos fueron introducidos en 1880 en la Guayana Francesa, provenientes de Indonesia. Posteriormente, en 1990, ingresaron a Brasil (Isla de Marajó, luego a Trinidad y Tobago, y finalmente a Venezuela y Argentina), para luego distribuirse por toda América. En la actualidad el búfalo se encuentra en todos los países del continente. Los últimos estados que incorporaron esta especie fueron Canadá y Chile. Los principales países en cantidad de cabezas son Brasil, Venezuela, Colombia y Argentina.

\section{Los búfalos en Argentina}

Los primeros búfalos llegaron a Argentina a principios del siglo XX, procedentes de Rumania y con destino a la Provincia de Entre Ríos, donde se intentó cruzarlos con vacunos para destinarlos a la producción de leche.

Al fracasar esta experiencia los búfalos prácticamente desaparecieron, excepto algunos que fueron liberados para la caza mayor. Los fallidos intentos de cruzar el búfalo con el ganado vacuno, ocurrieron al no haberse considerado la incompatibilidad cromosómica, dado que el búfalo posee -según su raza- entre 48 y 50 pares de cromosomas, dependiendo de ser "de pantano" o "de río", mientras que el bovino tiene 60 pares.

Debieron pasar varios años para que recién a comienzos de la década de 1980 se reanudaran las importaciones que, en pequeña escala, fueron realizadas desde Italia, Brasil y Paraguay, hacia la Argentina. Los ejemplares importados pertenecían a las razas Mediterráneo, Murrah y Jafarabadi.

En 1979 se importaron 100 animales de la razas Jafarabadi y Murrah. Cuarenta de ellos fueron enviados a la Estancia Santa Rosa ubicada en la localidad de Esquina, Provincia de Corrientes y los 60 restantes a las estancias La Florencia y La Alicia en la localidad de San Cristóbal, Provincia de Santa Fe ${ }^{10}$.

En 1983 se creó la Asociación Argentina de Criadores de Búfalos y en 1985 se registraron los primeros planteles puros abriéndose el primer libro de registros genealógicos. En los años 90 se produjeron grandes importaciones: más de 5.000 vientres y reproductores seleccionados desde Brasil, lo cual consolidó la cría del búfalo en el país. En Argentina se criaron tres de las razas de mayor importancia económica en el mundo: Murrah, Jafarabadi y Mediterránea, esta última representando el $70 \%$ de la población bubalina en Argentina.

La clase Mediterránea se originó en Italia, definiéndose como "raza" en Europa y demás zonas costeras del Mediterráneo. Sus colores comunes son el negro, gris oscuro, marrón oscuro y pizarra. Presenta cuernos medianos dirigidos hacia atrás y hacia los costados, con las puntas cerradas hacia arriba y hacia adentro formando una media luna.
La raza Murrah es originaria de la región del Punjab, en el noroeste de la India. Su nombre es una palabra hindú que significa espiralado y deriva de la forma de sus cuernos. Su color es negro azabache. Los cuernos son cortos, negros y espiralados desde su misma base, primero se orientan hacia los costados y luego completan la espiral hacia atrás. Es la raza más difundida en el mundo.

Por su parte, el nombre Jafarabadi deriva de la ciudad del mismo apelativo ubicada en la India, siendo animales de color negro, aunque son aceptables manchas blancas en la cabeza y en la parte inferior de las patas. Tiene una cabeza grande, con una frente prominente muy convexa, de corte rectilíneo. Los cuernos son pesados, gruesos, fuertes y anchos, que se orientan hacia abajo, atrás de los ojos, terminando con un rulo espiralado hacia atrás. Es la raza de mayor tamaño ${ }^{10}$.

Las tres castas enumeradas son de doble propósito, carne y leche, $\mathrm{y}$ a veces triple ya que en otros países se emplean para trabajo. En Argentina los búfalos son empleados mayoritariamente para la producción de carne y leche. No se utilizan para trabajo. La carne del búfalo no difiere con la del vacuno en su textura y palatabilidad, pero sí en la distribución de la grasa corporal. Las razas bubalinas poseen poca grasa entre los músculos y ninguna dentro de los mismos, por este motivo la carne es absolutamente magra. La grasa se concentra alrededor de los riñones y en el mesenterio.

Estudios realizados determinaron que las cantidades de hierro, fósforo y proteínas son mayores que las del vacuno, así como son más altos los niveles de ácidos grasos Omega 3, con propiedades anticancerígenas ${ }^{29}$. La leche de búfalos posee cerca de 3 veces mayor cantidad de materia grasa que la del vacuno, aproximadamente 6-16\%, produciendo 7-12 litros diarios de leche (equivalente a 21-36 litros de leche bovina, por el contenido graso), teniendo 30 a $40 \%$ más calorías que la de vaca y siendo de sabor dulce y color absolutamente blanco, por estar presente la vitamina $A$, mientras que la del vacuno posee caroteno (pro-vitamina $\mathrm{A}$ ).

Las razas más utilizadas en nuestro país para producción de leche son Murrah y Mediterránea, con sus respectivos cruzamientos. Esta producción de leche bubalina comenzó en 1992, y hoy en día los establecimientos lecheros están distribuidos en las provincias de Buenos Aires, Santa Fe, Tucumán, Corrientes, Formosa y Misiones. Estas empresas son generalmente tambosindustrias que destinan la producción a la elaboración de quesos, principalmente muzzarella.

De acuerdo a los datos oficiales aportados en diciembre de 2018 por el Servicio Nacional de Sanidad Animal (SENASA), la población de búfalos en Argentina es de 132.000 cabezas ${ }^{11}$. De las 23 provincias que componen el territorio nacional existe población bubalina en 20 de ellas y solo en tres provincias del extremo sur argentino (Chubut, Santa Cruz y Tierra del Fuego) no se crían búfalos.

Tomando en consideración la cantidad de búfalos que poseen las provincias argentinas, las mismas 
pueden ser agrupadas en: grandes, con más de 10.000 ejemplares (Formosa y Corrientes); medianas, entre 1.000 y 10.000 ejemplares (Chaco, Buenos Aires, Entre Ríos, Santa Fe y Misiones) y pequeñas, con menos de 1.000 ejemplares (Córdoba, Santiago del Estero, La Pampa, Neuquén, San Luis, Tucumán, Mendoza, La Rioja, Salta, Jujuy, San Juan, Catamarca y Río Negro).

Las dos provincias consideradas con grandes rodeos bubalinos son Formosa y Corrientes. Teniendo en cuenta la división del país por regiones, la del nordeste (NEA: Formosa, Corrientes, Chaco y Misiones) concentra el $80 \%$ de la población bubalina del país. La Provincia de Formosa es la que tiene la mayor cantidad de búfalos, ubicados principalmente en los departamentos de Formosa, Pilagá y Pirané.

La zona cuenta con cerca de 100 productores y existe un tambo de búfalas que produce quesos, yogurt y dulce de leche. La Provincia de Corrientes es la segunda en cantidad de búfalos pero la primera en número de productores del país con más de 200 criadores. Si se contabilizan los establecimientos con producción bubalina se superan los 200 ya que algunos productores presentan mayor cantidad de unidades productivas en la provincia. Los departamentos con mayor población bubalina son los de General Paz, Empedrado y San Miguel.

Si se analizan los establecimientos ganaderos dedicados a la producción de búfalos de las provincias de Formosa y Corrientes, las cuales concentran la mayor población ganadera, se pueden establecer en forma preliminar tres categorías diferenciadas por el número de animales que poseen. Así, la población se estratifica en pequeños productores (rango 1-50 cabezas), medianos (rango 51-300) y grandes (más de 300).

En Formosa se aprecia que el $50 \%$ de la población pertenece al estrato de grandes productores, en tanto que Corrientes solo presenta un $10 \%$ en esta franja, concentrando el $90 \%$ de las existencias bubalinas en los estratos mediano y pequeño. Formosa, cuenta con más de 41.000 búfalos, es la segunda provincia con mayor cantidad de cabezas en Argentina. Asimismo, es dable mencionar que el estado provincial cuenta con un rodeo de unos 500 animales cuyo fin es la difusión de la especie entre los distintos interesados, principalmente comunidades de menores recursos.

La Provincia de Chaco es la tercera en cantidad de búfalos, registrando más de 19.000 cabezas (superando los 40 productores), en establecimientos localizados mayoritariamente en el Departamento de San Fernando.

Misiones es la séptima provincia tomando en cuenta la cantidad de búfalos, pues posee cerca de 2.600 cabezas y 18 productores ${ }^{33}$. El departamento General Belgrano es el que cuenta con mayor cantidad de búfalos.

Entre las provincias consideradas medianas por la cantidad de búfalos se deben mencionar a Buenos Aires, Entre Ríos y Santa Fe (más de 4.500, 5.000 y 4.000 cabezas respectivamente) ${ }^{11}$.

\section{Infecciones en búfalos}

La crianza de búfalos ha estado aumentando a nivel mundial. La especie desempeña un papel importante en la producción de alimentos, especialmente en países que se encuentran cercanos a regiones tropicales ${ }^{6}$.

Dado que se adaptan con facilidad a los suelos húmedos y pantanosos, los búfalos representan una ventaja para los productores que poseen tierras en esas condiciones, las cuales resultan de difícil elección para los vacunos u otras especies productivas. No obstante lo anterior, la desventaja es que el ambiente húmedo también resulta ser adecuado para que se propaguen en él ciertas bacterias y parásitos, entre muchos otros agentes infecciosos.

Debido a su rusticidad, se supone que los búfalos son resistentes a muchas enfermedades; sin embargo hay infecciones a las que son susceptibles y pueden portar y transmitir estos gérmenes patógenos. Se sabe que los búfalos son susceptibles a los mismos agentes infecciosos que afectan a los vacunos en su gran mayoría $^{2}$

\section{Virus que causan enfermedades en búfalos}

BuVCo (corona virus bubalino). Es un virus "envuelto", que causa enfermedades entéricas y/o respiratorias en mamíferos y aves. Muestra una estricta relación genética y biológica con el coronavirus vacuno. Fue aislado en Italia, a partir de terneros bubalinos con gastroenteritis ${ }^{14}$.

$\boldsymbol{B I} \boldsymbol{V}$ (virus de inmunodeficiencia bovina). Causa una enfermedad crónica progresiva e induce signos de leucocitosis persistente, linfadenopatía, pérdida de peso y daño al sistema nervioso central. Además, hay evidencia de que $B I V$ puede causar inmunosupresión, desencadenando infecciones bacterianas secundarias y reducción de la respuesta inmune a las vacunas. $B I V$ también se asocia con la reducción de la producción de leche. Hay informes de infección con BIV en búfalos de Pakistán, Camboya y -recientemente- en Brasil ${ }^{2}$.

$B P X V$ (poxvirus de buffalo). Es un ADN-virus 1ineal, de doble cadena, agente causal de la búfalopoxina, enfermedad que ha sido reportada en el mundo y ponderada por ser una afección emergente y re-emergente en países productores de búfalos. En su forma leve la enfermedad se caracteriza clínicamente por lesiones localizadas en la ubre, pezones, dentro de los muslos, en la base de las orejas, sobre regiones parótidas, superficie interna del oído, colgajo y ojos; mientras que en la forma severa, las lesiones son indiscriminadas. Aunque la enfermedad no es responsable de aumento de la mortalidad, afecta negativamente a la productividad y a la capacidad de trabajo de los animales, resultantes en alta pérdidas económicas ${ }^{18,32}$ 
$B V D V$ (virus de la diarrea bovina). Afecta al ganado, principalmente a rumiantes, causando el síndrome de diarrea y generando problemas respiratorios e insuficiencia reproductiva. La infección durante la preñez puede resultar en resorción embrionaria, aborto, muerte de terneros al nacer, teratogénesis y nacimiento de terneros infectados persistentemente, que son el principal reservorio del virus en la naturaleza, el cual más tarde podría desarrollar enfermedad de la mucosa. Los pestivirus son capaces de cruzar las barreras de las especies e infectar un amplia gama de hospedadores. Se ha estudiado la presencia de $B V D V$ en búfalos infectados naturalmente que presentaban signos clínicos compatibles con los de este agente viral. Si bien no pudo confirmarse que los signos clínicos eran debidos a la infección con $B V D V$, se demostró que dicho agente viral puede infectar y replicar en búfalos. Mediante inmuno-histoquimica y RT-PCR (reverse transcription-polymerase chain reaction) se confirmó la co-circulacion de los subtipos la y $1 \mathrm{~b}^{8}$. El principal hallazgo fue la detección de $B V D V-1 \mathrm{lb}$ en dos rebaños de búfalos. Este subgrupo $B V D V-1 \mathrm{~b}$ podría estar correlacionado con la situación geográfica de origen de estos virus. La mayoría de los aislamientos italianos reportados hasta la fecha estan relacionados con el mismo subgenotipo ${ }^{25}$. En 2018, investigadores brasileños identificaron infección activa por el subgenotipo $l b$ de $B V D V$ en rebaños de búfalos lecheros en Brasil mediante la técnica de RT_PCR ${ }^{27}$.

$F M D V$ (virus de la fiebre aftosa). Es un picornavirus compuesto por una doble cadena de ARN de diferentes tamaños. Causa enfermedad vesicular aguda altamente contagiosa en el ganado doméstico y en las especies silvestres. Si bien no hay reportes en $B$. bubalis de este virus, los búfalos africanos son los portadores principales del virus de la fiebre aftosa en los ecosistemas de sabanas africanas, donde la enfermedad es endémica ${ }^{24}$. El virus de la fiebre aftosa es un miembro del género Aphthovirus de la familia Picornaviridae. Existen siete serotipos inmunológicamente distintos: O, A, C, SAT 1, SAT 2, SAT 3 y Asia 1 (y más de 60 cepas dentro de estos serotipos). Los serotipos y cepas del virus de fiebre aftosa varían dentro de cada región geográfica. El serotipo $\mathrm{O}$ es el más común mundialmente. El ganado vacuno y los búfalos africanos son los huéspedes de mantenimiento habituales para el este virus en África. Se cree que actualmente los búfalos africanos, sólo llevan el serotipo SAT. La transmisión sexual podría ser una vía importante de propagación para los virus tipo SAT en las poblaciones de búfalos africanos. Los mismos pueden ser portadores durante cinco años como mínimo y el virus puede persistir en un hato, hasta 24 años. Las infecciones con los virus tipo SAT en búfalos africanos son a menudo subclínicas, aunque han sido reportadas pequeñas lesiones en la boca $\mathrm{y} / \mathrm{o}$ patas.
$B P V$ (virus del papiloma vacuno). Son virus pequeños envueltos de DNA doble cadena. La primera detección fue en India, en el rumen de los búfalos, donde se encontraron verrugas variadas en tamaño y forma, las cuales fueron asociadas a BPV5, BPV2 y BPV1 ${ }^{30}$.

$\boldsymbol{R} \boldsymbol{V} \boldsymbol{F} \boldsymbol{V}$ (virus de la fiebre del valle). Es una enfermedad viral, aguda y febril transmitida por vectores humanos y por algunas especies de rumiantes domésticos, con morbilidad y mortalidad significativas. El virus se caracterizó hace aproximadamente 80 años en Kenia y se diseminó en seres humanos, ovejas y ganado vacuno, en algunas latitudes como África, Arabia Saudita y Yemen. Luego la infección se trasladó a Turquía, donde se detectó mayoritariamente en búfalos ${ }^{19,26}$.

$R A B V$ (virus de la rabia). Este virus presenta un genoma de ARN de sentido negativo, con 5 genes. Todos los animales de sangre caliente, incluyendo mapaches, zorrillos, murciélagos y zorros, son susceptibles a RABV, y los perros domésticos actúan como su principal reservorio y transmisor ${ }^{38}$. El RABV fue extraído del cerebro de búfalos en China y caracterizado mediante inmunofluorescencia directa y RT-PCR ${ }^{35,36}$.

PIV3 (virus parainfluenza tipo 3). Es un virus envuelto en ARN de sentido negativo, monocatenario, dentro del género respirovirus de la familia paramyxoviridae. El género respirovirus incluye los virus parainfluenza humana tipos 1 y 3 (HPIVl y HPIV3, respectivamente), virus sendai (PIV1 murino) y virus parainfluenza vacuno tipo 3 (BPIV3).

BPIV3 (virus parainfluenza vacuno tipo 3). En algunos casos, cuando los animales son sometidos a condiciones estresantes, la infección con BPIV3 puede contribuir al daño tisular y a la inmunosupresión, resultando en una bronconeumonía severa por infecciones bacterianas secundarias. La enfermedad resultante es parte del complejo de enfermedad respiratoria bovina (BRDC) y se considera como la afección más importante asociada con engorde a corral en los Estados Unidos y posiblemente en todo el mundo. Las infecciones con BPIV3 pueden variar considerablemente, desde casos asintomáticos hasta enfermedad respiratoria severa. En la mayoría de los casos en los que BPIV3 está implicado en la enfermedad, los signos clínicos habituales incluyen tos, fiebre y secreciones nasales. BPIV3 se aisló de búfalos de agua de Argentina, desde hisopados nasales y vaginales en un caso donde los animales presentaron signos respiratorios y reproductivos ${ }^{21}$. Hay pocos informes sobre la circulación de BPIV3 en Argentina. Las reconstrucciones filogenéticas basadas en la alineación de las secuencias de nucleótidos del gen$\mathrm{M}$ demostraron que los virus parainfluenza aislados de búfalos se agrupan en el genotipo $\mathrm{B}^{21}$. Hasta ahora, este genotipo solo había sido reportado en Australia. La caracterización serológica y molecular de los virus parainfluenza aislados desde búfalos muestran que es- 
tos virus son parainfluenza vacuno y más similares al genotipo B que al A (cepa de referencia SF).

H9N2 (avian influenza virus). Durante el año 2019 en Irán se detectaron anticuerpos contra el virus H9N2 aviar en búfalos de agua por la técnica de inhibición de la hemoaglutinación. Esto sugiere que puede haber un ciclo en búfalos de agua del virus H9N2 aviar. Los resultados también sugieren que la transmisión del virus H9N2 de especies aviares a búfalos de agua puede permitir la adaptación viral a los mamíferos. Este problema destaca la importancia de prestar mayor atención a este dominio. Se requiere investigación adicional para probar esta hipótesis e investigar más aspectos epidemiológicos y la probable patogénesis de la transmisión del virus a través de las especies y sus factores de riesgo relacionados ${ }^{7}$.

$B$ BHV1 (herpesvirus bubalino tipo 1). Es un virus de ADN envuelto en doble cadena, perteneciente a la familia alfa-herpes-virus. Está estrechamente relacionado con BoHVl y BoHV5, agentes causales de la rinotraqueitis infecciosa bovina. BoHV1 es responsable de una amplia gama de síndromes clínicos en el ganado, como rinotraqueitis, aborto, vulvo-vaginitis pustular y encefalitis. Por el contrario, BuHV1 solo se ha asociado con una enfermedad subclínica en búfalos de agua (B. bubalis). En el año 2004, en Italia se aisló el virus en hisopados nasales de búfalos. Recientemente se obtuvo otro aislamiento de BuHVl a partir hisopados de prepucio de búfalos adultos ${ }^{31}$. En 2013, BuHV1 fue detectado en Europa ${ }^{3}$. En este estudio se analizaron fetos de búfalos recolectadas de cuatro granjas del sur de Italia. La presencia de herpesvirus se investigó mediante la técnica de PCR. El ADN de herpes fue detectado en la placenta y el pulmón del feto, mientras que el resto de los tejidos fueron negativos. En Argentina, un grupo de investigadores reportó cinco aislamientos analizando 225 muestras de cuatro granjas diferentes en el noreste del país. Uno de los aislamientos se obtuvo de las secreciones nasales y los otros desde secreciones vaginales ${ }^{22,23}$. El último aislamiento de BuHV1 reportado fue obtenido por reactivación experimental ${ }^{28}$.

Saltos entre especies y evaluación de campos mixtos

Otro aspecto importante de analizar surge de la convivencia de búfalos con otras especies de animales domésticos, cuando se los introduce en potreros compartidos. Al desconocerse las enfermedades que portan los búfalos y las que podrían resultar susceptibles, se crea un desequilibrio entre los agentes etiológicos, el medio ambiente y los hospedadores susceptibles (el búfalo y otras especies), pudiéndose generar un serio problema zoo-sanitario y poner en riesgo la salud de los productores.

Se han realizado estudios de infección cruzada para tener mayor conocimiento sobre los riesgos de in- fecciones agudas y latentes en ganado bubalino, con diferentes agentes infecciosos entre diversas especies de rumiantes.

Si bien hay antecedentes de aislamientos de parainfluenza 3 en búfalos de agua de África, éstos fueron caracterizados sólo virológicamente. En Argentina (2012) se aislaron PIV3 de dos búfalos de agua desde secreciones nasales y vaginales. Estos aislamientos de búfalos, por su agrupamiento se caracterizaron como PI3 vacunos ${ }^{21}$.

Con respecto a pestivirus, mediante análisis serológicos se han reportado en más de cuarenta especies de rumiantes, encontrándole la mayor prevalencia serológica en: búfalo (Syncerus caffer), kudu (Tragelaphus strepsiceros), diferentes razas de antílopes como Taurutragus oryx, Kobusellipsi prymnus, Redunca arudinum, Hippotragus niger, ñu azul (Connochae testaurinus), gacela (Antidorcas marsupialis) y duiker gris (Sylvica pragrimmia).

En África se aisló BVDV a partir de búfalos (Syncerus caffer) sin manifestaciones clínicas. Respecto a los pestivirus, en búfalos de agua se detectó BVDV en fetos abortados del sur de Italia ${ }^{25}$. Luego se reportaron aislamientos de BVDV tipo lb en búfalos de agua en Filipinas.

En nuestro país, estudios realizados en el Instituto de Virología del CICVyA confirmaron, mediante análisis serológicos, la presencia de una elevada seroprevalencia de infección con BDV en búfalos de agua ( $B$. bubalis), provenientes de la Provincia de Corrientes. Por otra parte, aunque no fue posible el aislamiento mediante técnicas moleculares convencionales, sí fue posible detectar la presencia de ácido nucleico viral en animales seronegativos, demostrándose -por primera vez- la presencia de búfalos $\mathrm{PI}^{8}$.

Si bien los datos serológicos y la detección de genomas virales reportados no determinan susceptibilidad, evidencian la existencia de transmisión de pestivirus inter-especie, tanto entre especies domésticas como salvajes. Aunque la infección por BVDV en búfalos está serológicamente documentada según lo descrito anteriormente, existen escasos reportes acerca de aislamientos y de la importancia de la infección por BVDV en esta especie animal.

La familia Herpesviridae incluye casi 200 virus aislados de varias especies hospedadoras. Se ha informado que los herpesvirus de rumiantes tienden a cruzar la barrera de las especies y adaptarse a otras especies. Estudios realizados demostraron la susceptibilidad del ganado vacuno a la infección con BuHVl por medio de ensayos experimentales de infección natural y por transmisión de búfalos infectados a terneros ${ }^{23}$.

Debido a la elevada cantidad de campos de producción mixta que existen actualmente en Argentina, resulta importante estudiar la circulación tanto de BuHV1 como de BoHV en ambos rodeos ${ }^{23}$. Una vez reportada la susceptibilidad de los bovinos a herpesvirus bubalino, resta conocer si los búfalos son susceptibles a los herpesvirus bovinos y determinar el rol del 
búfalo en la patogenia de los herpesvirus vacunos, evaluando su rol en la transmisión de estas infecciones a bovinos vírgenes susceptibles, así como el impacto en el campo de la co-circulacion de herpesvirus vacuno y bubalino, especialmente en sistemas de producción mixta búfalo-vacuno.

Esta información permitiría un diseño racional de medidas sanitarias que puedan disminuir los riesgos de la co-circulación viral y cruces de barreras interespecies.

\section{Bacterias que causan enfermedades en búfalos}

Mycobacterium bovis es el agente causal de la tuberculosis, tanto en búfalos como en vacunos. Tal enfermedad causa problemas respiratorios y reproductivos, depresión del sistema inmunológico y disminución de la condición corporal. Mycobacterium genera afecciones de curso crónico en personas y animales. Dicha bacteria se ha podido identificar en búfalos de Pakistán, Italia, Argentina y Cuba. En este último país se han llevado a cabo pruebas experimentales de hipersensibilidad cutánea (prueba de tuberculina) para evaluar una forma de diagnóstico práctico y económico que, al parecer, ha sido satisfactorio. Sin embargo, falta mucho por evaluar ya que el grosor de la piel del búfalo es diferente a la del vacuno, además de que se han aislado también otras bacterias en órganos colectados en las autopsias ${ }^{17}$. Esta enfermedad es una zoonosis responsable de significativas pérdidas económicas en el comercio de búfalos ${ }^{4}$.

Brucella $s p$ es el agente patógeno que produce la brucelosis, infección zoonótica que se transmite en animales por ingestión de alimentos contaminados, por contacto directo con especies infectadas, o por inhalación de aerosoles. Las brucellas son cocobacilos aeróbicos intracelulares y se localizan en los órganos reproductivos de los animales huéspedes, causando abortos y esterilidad. En India, Italia, Sri Lanka y Argentina se han hallado anticuerpos contra la brucelosis y se ha aislado el agente que la transmite en hatos de búfalos e incluso en su leche. Ello implica un alarmante riesgo de contagio para el personal que elabora quesos artesanales sin pasteurizar, y más todavía para la población que los consume, puesto que la principal vía de contagio es la digestiva. Por otra parte, existen diferentes especies de esta bacteria, las cuales afectan a géneros animales en particular. Así, la coexistencia con búfalos puede complicar su control o erradicación al producirse infecciones cruzadas entre especies animales ${ }^{17}$.

Leptospira sp es el agente causal de la leptospirosis, enfermedad zoonótica de importancia mundial que afecta a seres humanos y animales. Por tener como hábitat los lugares inundables y los climas húmedos, Leptospira $s p$ hace que los búfalos de agua sean susceptibles de contagio y actúen como portadores y transmisores de la espiroqueta, pues los animales infectados la eliminan por la orina. Una de las conductas defensivas de los búfalos es orinar mientras se los mantiene confinados o cuando se lleva a cabo algún tipo de manejo. Ellos orinan agitando la cola, constituyendo esa acción la vía de contagio para el hombre y otros animales con los cuales comparten instalaciones como bebederos o afluentes de agua (abrevaderos, lagunas). La leptospirosis se ha estudiado en ganado bubalino de países como Italia, Sri Lanka, Argentina y Brasil, descubriéndose que puede causar la muerte al animal a los pocos días después del contagio, así como causar abortos y fallas reproductivas ${ }^{17}$. La principal fuente de infección es el contacto ambiental indirecto con leptospiras excretadas de la orina del hospedador. En Argentina, se reportaron búfalos con seropositividad a Leptospira interrogans ${ }^{16}$.

Pasteurella multocida es una bacteria que causa septicemia hemorrágica (pasteurellosis), importante enfermedad de los búfalos, los cuales son muy susceptibles y mueren en gran número al ser infectados. Una hinchazón caliente, dura y dolorosa en la región ventral, es la señal más evidente de la enfermedad. Los animales exhiben hinchazón de la lengua y sus membranas mucosas están hiperémicas, con respiración laboriosa y dolorosa. Se trata de una enfermedad febril aguda que causa la mortalidad en los animales más jóvenes. En la fase febril el daño hepático causa bilirrubinemia y disminución del colesterol ${ }^{15}$.

Staphylococcus aureus infecta a búfalos y vacunos causando infecciones, especialmente mastitis. El microorganismo tiene la capacidad de generar contaminaciones múltiples debido a la expresión de varias toxinas, factores de virulencia y proteínas de adhesión a la pared celular. Dicha bacteria es capaz de sobrevivir en la ubre, a la cual inflama frecuentemente.

Escherichia coli. En Italia y Turquía se ha identificado a esta bacteria y a un rotavirus como responsables de graves diarreas en búfalos jóvenes. Ello implica un riesgo para los productores, debido a la posibilidad de contagio al ingerir alimentos contaminados con las heces de estos animales, aunque también puede ocurrir que sean las personas quienes contagien a los animales ${ }^{17}$.

\section{Parásitos que causan enfermedades en búfalos}

Como se mencionó, búfalos y vacunos a menudo conviven en las mismas áreas ganaderas y son expuestos a los mismos endo y ectoparásitos. Como los búfalos son considerados más resistentes a algunas infecciones, los controles sanitarios son menos exigentes que para los vacunos en la misma región.

La mosca del búfalo (Siphona sp) es el principal ectoparásito. La pediculosis, causada por los piojos chupadores (Hematopinus tuberculatus), sucede frecuentemente entre los búfalos, y la sarna sarcópti- 
ca (Sarcoptes scabiei var. bubalus) es una grave enfermedad, especialmente entre terneros y durante las temporadas de sequía, cuando las oportunidades para revolcarse están restringidas.

Theileria mutans y $T$. laurencei son dos protozoarios productores de theileriosis, enfermedad transmitida por las garrapatas. Se sabe que los búfalos son portadores de estos dos patógenos siendo T. laurencei el causante de afecciones en los vacunos cuando comparten el pasto con los búfalos. Se ha reportado que estos últimos constituyen un potencial reservorio para la garrapata común del ganado vacuno (Rhipicephalus Boophilus microplus), quien puede completar el ciclo en B. bubalis ${ }^{5}$.

Anaplasma sp y Babesia $s p$ son destructoras de eritrocitos. La babesiosis bovina ("tristeza") es causada por varias especies de Babesia, constituyendo una de las enfermedades más importantes del ganado en casi todas las regiones de clima tropical y subtropical. En los búfalos, la babesiosis se reportó por primera vez en 1984 en campos de Corrientes, Argentina, por infecciones de Anaplasma sp y Babesia sp (esta última por las variedades B. Bovis y B. bigémina ${ }^{20}$. En 2008, la babesiosis bubalina fue detectada mediante cELISA y PCR en diferentes campos de la Provincia de Corrientes.

\section{Conclusión}

Lo descrito en esta revisión confirma la susceptibilidad de los búfalos de agua a las infecciones causadas por muchos de los agentes patógenos que afectan principalmente al rodeo vacuno $\mathrm{y}$, por lo tanto, su posible rol como huésped o reservorio de los mismos.

Si bien los búfalos de agua pertenecen a una especie diferente a los bovinos, en base a lo descrito en esta revisión, debería ser estudiada la posibilidad de emplear en búfalos las mismas vacunas utilizadas para vacunos, en pos de desarrollar un calendario sanitario para estos últimos.

La aplicación de protocolos que reduzcan el estrés en distintos manejos y sistemas de producción, sumados a un racional y eficiente control sanitario, redundarían tanto en la mejoría del bienestar animal, como en la disminución de incidencia de infecciones.

\section{REFERENCIAS}

1. Abdellah MR, Hamed MI, Ibrahim DR, Rateb HZ. 2014. Serum biochemical and haematological reference intervals for water buffalo heifers. J South Afr Vet Ass 85 : $1-8$.

2. Albernaz TT et al. 2015. Molecular detection of bovine immunodeficiency virus in water buffaloes (Bubalus bubalis) from the Amazon region, Brazil. Trop Anim Health \& Prod 47: 1625-1628.

3. Amoroso MG et al. 2013. Bubaline herpesvirus-1 associated with abortion in a mediterranean water buffalo. Res Vet Sci 94: 813-816.
4. Barbosa JD et al. 2014. Tuberculosis prevalence and risk factors for water buffalo in Pará, Brazil. Trop Anim Health \& Prod 46: 513-517.

5. Benitez D, Cetra B, Florin CM. 2012. Rhipicephalus (Boophilus) microplus ticks can complete their life cycle on the water buffalo (Bubalus bubalis). J Buff Sci 1: 193197.

6. Borghese A, Nazzu A. 2005. Buffalo population and strategies in the world. In: Buffalo production \& research, chapter I, p.1-39, Ed. Instituto Esperimentale per la Zootecnia. FAO, Roma, $315 \mathrm{p}$.

7. B.Tajik J, Tavacoli H, Soltani D. 2019. Serological investigation of H9N2 avian influenza virus in slaughtered water buffaloes (Bubalus bubalis) in Khuzestan, Iran. Arch Razi Inst 74: 77-82.

8. Craig MI et al. 2008. Detection of bovine viral diarrhoea virus (BVDV) nucleic acid and antigen in different organs of water buffaloes (Bubalus bubalis). Res Vet Sci 85: 194196.

9. Correa H. 2005. Código de buenas prácticas de producción de leche para Colombia. Univ. Nac. de Colombia (sede Medellín). http:/www.slideshare.net/JuanDavid28/ codigo-colombiano-de-buenas-practicas-de-manejo-enel-ordeo (con acceso 23/03/2012).

10. Crudeli G et al. 2004. Búfalos en Argentina. Orient. Graf. Edit. SRL, Buenos Aires, $230 \mathrm{p}$.

11. Crudeli G et al. 2014. Pasado, presente y futu ro del búfalo en Argentina. Rev Vet 25: 140-145.

12. Delacruz L et al. 2018. The welfare of water buffaloes during the slaughter process: A review. Livestock Sci 212: 22-33.

13. DeRosa G et al. 2009. Behavior and milk production of buffalo cows as affected by housing system. J Dairy $S c i$ 92: 907-912.

14. Decaro N et al. 2010. Characterization of bubaline coronavirus strains associated with gastroenteritis in water buffalo (Bubalus bubalis) calves. Vet Microbiol 145: 245-251.

15. Denipitiya DT. 2017. Identification of cattle, buffaloes and rodents as reservoir animals of Leptospira sp in the district of Gampaha, Sri Lanka. BMC Research Notes 1: 5.

16. Dellamea M, Jacobo RA, Draghi MG, Cipolini MF. 2008. Identificación de infecciones con Leptospira $s p$ en búfalos de la región noroeste de Corrientes, Argentina. Comunic Cientif \& Tecnol, UNNE, Corrientes, Argentina, 4-6.

17. Domínguez GA, Romero SD, Martínez DI, García VZ. 2013. Los búfalos de agua y las enfermedades infecciosas. Rev Divulg Cient \& Tecnol Univ Veracruzana (México) 26 : 2.

18. Goraya MU, Qureshi A, Abbas M, Ashraf M, Munir M. 2015. Isolation of buffalo poxvirus from clinical case and variations in the genetics of the B5R gene over fifty passages. Virus Genes 51: 45-50.

19. Gür S et al. 2017. The first serological evidence for Rift Valley fever infection in the camel, goitered gazelle and anatolian water buffaloes in Turkey. Trop Anim Health Prod 49: 1531-1535.

20. Jacobo RA, Cipolini MF, Storani CA, Martínez DE, Martínez EI. 2005. Infección con el complejo tristeza en 
búfalos. Comunic Cientif \& Tecn UNNE, www.unne.edu. ar/unnevieja/Web/cyt/com 2005/4.../V-063_Falta\%20Corregir.pdf.

21. Maidana $\mathbf{S}$ et al. 2012. Isolation and characterization of bovine parainfluenza virus type 3 from water buffaloes in Argentina. BMC Vet Res 8: 83.

22. Maidana $S$ et al. 2014. First report of isolation and molecular characterization of bubaline herpesvirus (BuHV1) from Argentinean water buffaloes. Arch Virol 159: 29172923.

23. Maidana S et al. 2016. Cattle are a potential reservoir of bubaline herpesvirus 1 (BuHV1), Vet Rec Open 1, 1-6.

24. Maree F et al. 2016. Differential persistence of foot-andmouth disease virus in african buffalo is related to virus virulence. $J$ Virol 29: 5132-5140.

25. Martucciello A et al. 2009. Detection of bovine viral diarrhea virus from three water buffalo fetuses (B. bubalis) in southern Italy. $J$ Vet Diagn Invest 21: 137-140.

26. Manyibe T et al. 2008. Prevalence of antibodies against Rift Valley fever virus in Kenyan wildlife. Epidemiol Infect 136: 1261-1269.

27. Paixão SF et al. 2018. Bovine viral diarrhea virus subgenotype $1 \mathrm{~b}$ in water buffalos (Bubalus bubalis) from Brazil. Trop Anim Health Prod 50: 1947-1950.

28. Preziuso S, Marenzoni ML, Thiry J, Thiry E, Cuteri V. 2018. Molecular characterization and virulence of an alpha herpes virus isolated from a BoHV1 gB-seropositive and $\mathrm{gE}$-seronegative italian buffalo. Vet Microbiol 221: 2732.

29. Regetti J, Rodriguez R, Silva C. 1993. Retrospectiva histórica y producción de búfalos en Venezuela. $I X$ Cursillo bovinos de carne (Plasse D. y Peña N. Ed.), Univ. Cen- tral de Venez., Fac. Cs. Veterinarias, Maracay, Venezuela, $179-197 \mathrm{p}$.

30. Somvanshi R, Pathania S, Nagarajan N, Pangty K, Kumar P. 2012. Pathological study of non-neoplastic urinary bladder lesions in cattle and buffaloes: A preliminary report. Trop Anim Health \& Prod 44: 855-861.

31. Stahel AB, Baggenstos R, Engels M, Friess M, Ackermann M. 2013. Two different macaviruses, ovine herpesvirus-2 and caprine herpesvirus-2, behave differently in water buffaloes than in cattle or in their respective reservoir species. Plos One 27: 8-12

32. Swanepoel A. 2007. Nosocomial buffalo poxvirus infection, Karachi, Pakistan. Emerg Infect Dis 13: 902-904.

33. Tajik J, Tavakoli H, Soltani D. 2019. Serological investigation of $\mathrm{h} 9 \mathrm{n} 2$ avian influenza virus in slaughtered water buffaloes (Bubalus bubalis) in Khuzestan, Iran. Arch Razi Inst 74: 77-82.

34. Tejedor F. 2014. Futuro del búfalo en Argentina. PDF DocPlayer. https:// docplayer.es/.../115091495.

35. Thiry $\mathbf{J}$ et al. 2006. Ruminant alpha herpes viruses related to bovine herpesvirus 1. Vet Res 37: 169-190.

36. Valdes MA et al. 2011. Bubalinocultura de las Américas, Ed. Moglia (Corrientes, Argentina), ISBN 978-987-619.

37. Zapata $\mathrm{R}$ et al. 2009. Frequency of Trypanosoma sp. infections in water buffaloes (Bubalus bubalis) in four buffalo cattle farms of Barrancabermeja, Colombia. Rev Colomb Cs Pec, http://rcep.udea.edu.co 22: 25-32

38. Zhang KS et al. 2011. Diagnosis and molecular characterization of rabies virus from a buffalo in China: a case report. Virology $J$ 8: 101. 